\title{
Scaffolding Chinese College Students' English Learning through Mind Mapping
}

\author{
Shu Zhou \\ Foreign Language school of China West Normal University \\ Shunqing District, Nanchong City, Sichuan province, China \\ suki1222@126.com
}

\begin{abstract}
This paper probes into the difficulties of listening and reading comprehension Chinese English learners confront and demonstrate a college English learning mode based on mind mapping, attempting to find an efficient self-learning way for Chinese English learners.
\end{abstract}

Keywords: mind mapping, Chinese English learners, logic, Listening and reading comprehension

\section{INTRODUCTION}

Chinese and English are two languages classifying into two different language systems. Before entering college, most of Chinese students learn English through a bottom-up process, paying great attention to words, sentences and grammar points teachers deliver. Right now in college, they find that their poor listening and comprehension ability hinder further learning. College English is a compulsory course for non-English majors in Chinese universities. However, the teaching and learning of it are far from satisfactory. There are large classes with limited time and resources. The levels of students vary in English, but comparatively most of them are poor in listening and reading. At present, The Requirement for College English Teaching calls for cultivating students' overall communication competence, and develop their autonomous learning ability. Among the four skills of English, listening comes first and it becomes the bottleneck problem for English learners in college. A class survey indicates students spend $65 \%$ of time of English learning in memorizing words, only 9\% left for listening and speaking. Most of their goals of leaning English are to pass CET4 or CET6 (Chinese English Proficiency Tests). The survey also shows them have great trouble in listening and reading comprehension, failing to grasp the gist and key information. Teachers have already noticed it, and have achieved a lot on the improvement of instruction. College English, however, lies in two parts which consist of teaching and learning. As for the growing concern of learners' autonomy, how to shift students from a passive receiver to an active thinker and problem-solver, how to lead them to monitor the process of learning, and how to help them adopt to mind mapping are the key to tackle the bottleneck problem.

\section{Mind MAPPIng AND English LANGUAGE COMPREHENSION}

\subsection{Theoretical Basis of Mind Map}

Mind map is created by the British psychologist Tony Buzan in the 1960s, and it is an emerging brain science. It is a diagram used to visually organize information. A mind map is often created around a single concept, drawn as an image in the center page, to which associated representations of ideas such as images, words and parts of words are added [1]. Major ideas are connected directly to the central concept, and other ideas branch out from those. At first, it took only as a new method of note taking, then gradually it developed into a tool for thinking and learning. 
Tony Buzan put forward the concept of mind map on the basis of brain research, which emphasize the way of thinking should be in accordance with the way of brain's function. Our brain form in a tree structure, so does the mind map. The finished mind map is like a brain's structure, the content of thinking is high-lightened by the processing of key information within the map.

Mind map is a graphic thinking tool. Research shows the processing of pictures of our brains are one thousand times better than the processing of language. Mind mapping has one center, from which we can construct our thinking in a logical and systematic way with lines, colors, marks and pictures linking the key words like a map. Besides, psychologists and brain scientists tell us brain is divided into two parts according to its function. The left part is good at languages, logic and numbers, while the right part is skilled at music, pictures and imagination [2]. On the basis of analyzing the rule of human's memory and logic, mind map connect language with picture, logic with imagination, which make full use of our mind in a potential way.

\subsection{Mind mapping in English Language Comprehension}

The characteristic of English language is logical and plain [3], which is exactly similar to the feature of mind map. Chinese English learners, however, find it hard to understand this logical language for there is a huge difference between Chinese and English ways of thinking. As for Chinese way of thinking, our ancestor Confucius, the founder of Confucianism, has great influence on it. His core thoughts are about ethics and moralities so as to better regulate the interpersonal relationship in feudal society, which contributes the intuitive and subjective thinking mode of Chinese language. On the other hand, the logic and objective thinking mode of English language came into being with the basis of scientific experiments, with the form of logical analysis and reasoning [4]. To be more vividly, English is like a tree with main bodies and layers of brunches in an organized form, while Chinese is more like a running river, which turns and twists anytime anywhere without specific form. Therefore, as Chinese English learners, the first and foremost thing they need to do to comprehend English is to know the characteristics of English and change their way of thinking into a more logical way. So far till they are in college now, they already have a basic foundation of English words and grammar. If teachers can introduce them a new way of learning, using mind map for scaffolding their listening and reading comprehensions, they will learn English in a more efficient way.

Language learning follows the process from input to output. Tony Buzan's mind map can be applied into information processing ,especially to process English which has the feature of logic ,because mind mapping can demonstrate a clear and logical pictures with key words, lines, marks and so on which present the thinking process of the language in a systematic way. We have two ways of language input, listening comprehension and reading comprehension, both of which train our brain to process the understanding [5]. Hence how to cultivate Chinese English learners' listening and reading comprehension through mind mapping in an active way? Based on teaching practice, I'll illustrate the application of mind map to Chinese learners in the following part.

\section{Cultivating Chinese English Learners' Listening and Reading Comprehension THROUGH MIND MAPPING}

\subsection{Note Taking with Mind Map in Listening and Reading Comprehension}

Note taking reflects the understanding and memory of certain listening and reading information. Traditional note taking is full of words, emphasizing the language points but lacking of logical connections and graphic information. Without key words, clear logic and with too much of details, it can reflect little about personal processing through your understanding, and do nothing to stimulate your brain for memorizing and thinking. Therefore, only the note with personal analysis reflecting one's 
comprehension and creativity can be the well-qualified one.

Mind map note taking is superior to traditional note taking, for it takes advantage of the multiple functions from both sides of our brains, which complies with the natural way of thinking mode as well as the English language features. So during note taking, we can write down key words only, but not the long sentences, using graphs, marks, colors and lines to form a logic structure of information in English. In listening comprehension processing, we should teach students the strategy of shortening words and using marks for better catching up with the speed of the information. In reading, students are supposed to enjoy more space for drawing the mind map with key words according to their personal interests. In this way, it is time-saving and key points emphasizing, not only having combed our logic, but also grasped the content of information in a structural way.

Listening comprehension mind map (Samples from teachers' instruction)
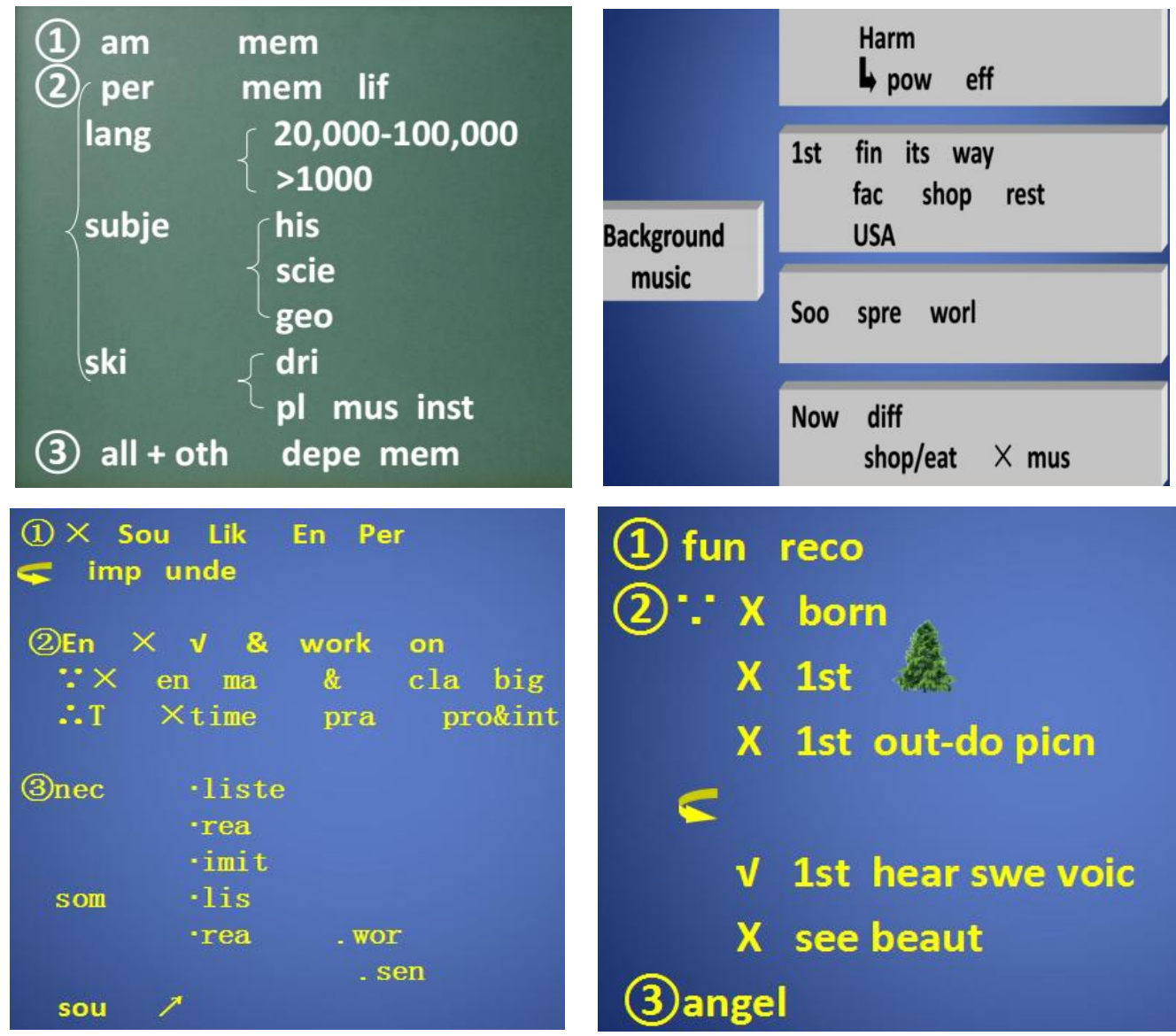

Reading comprehension mind map (Samples from students' projects)
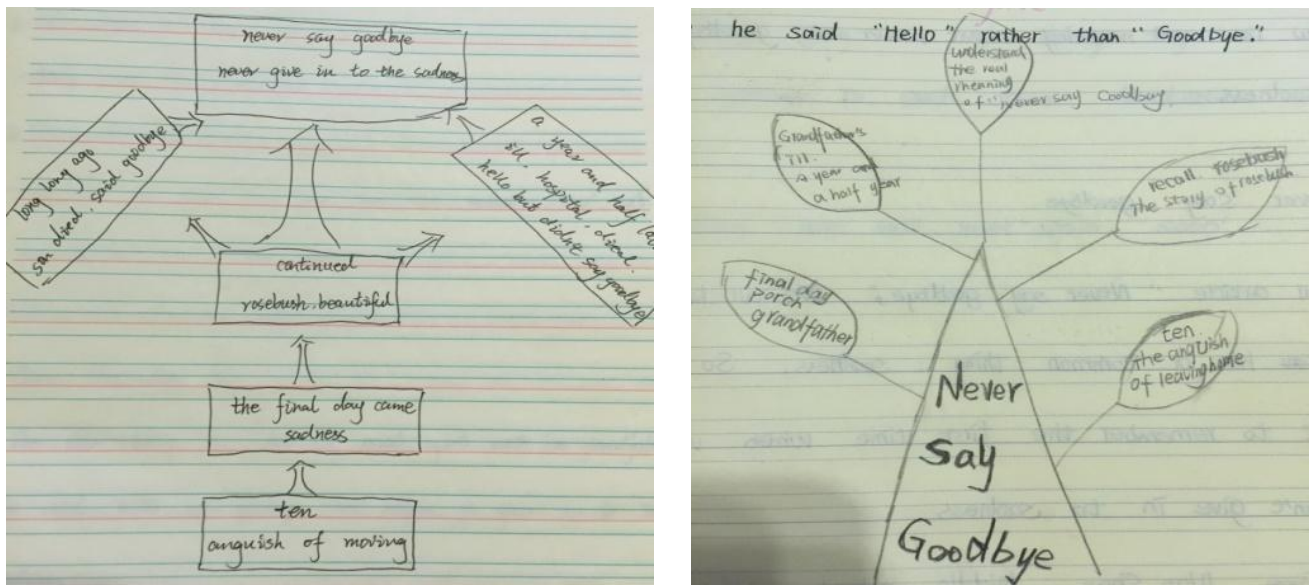

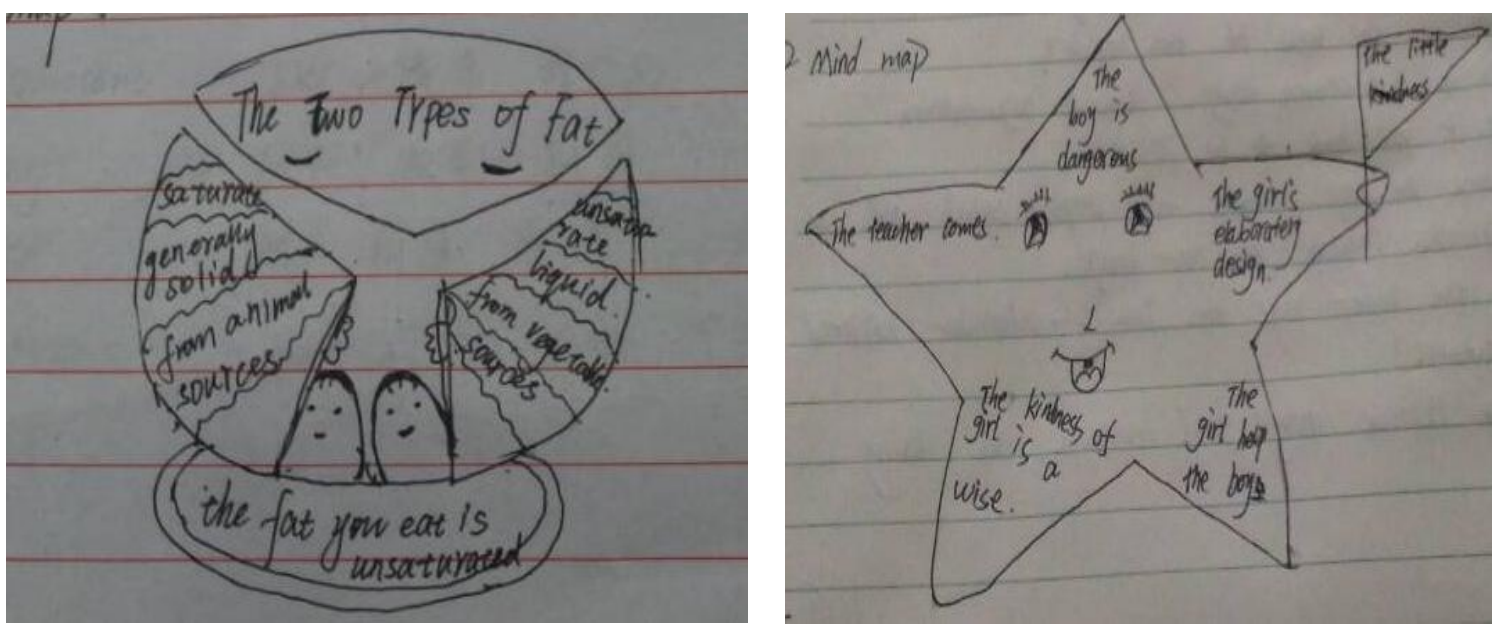

\subsection{The English Learning Mode with Mind Map}

Chinese students get used to the mode of teaching by holding the hands which hinders them to become active learners. Mind map can stimulate their self-learning motivation and become critical thinking learners. As for teachers we should provide students the efficient way of learning English through comprehensive input to creative output. And all of them require the clear and logical understanding of English. Mind map, apparently, becomes the core to integrate the four parts into a systematic structure, through which learners can process English listening and reading comprehension with a result of a mind map , and then they can also express themselves in speaking and writing based on this mind map in a logical and creative way. They can actively learning English from listening to speaking, from reading into writing . This integrated mode of learning English best solve Chinese students' problem for they are not good at thinking in a logical way as English should be. Mind map is a tool that bridges the gap between the river-like Chines language and a tree-form English language, helping Chinese to think in an English way. Only in this way can we grasp the nature of English, and can we learn real English for better communication.

Scaffolding English learning mode with through map

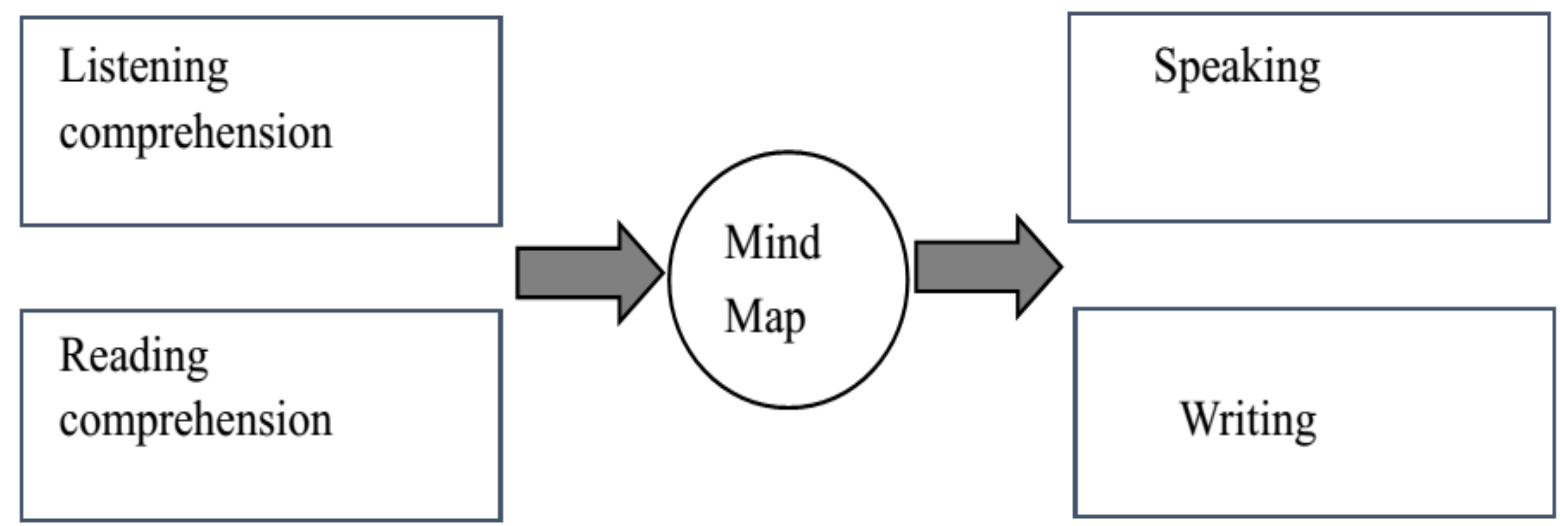

\section{Conclusion}

To deal with the poor listening and reading comprehension for Chinese English learners, mind map can bridge the gap between the different way of thinking in Chinese and English. Through clear comprehending of the input information, students can express their understanding out with their own ideas in a more logical way. Most importantly, they are learning English in an English way of thinking but not Chinese way or Chinglish way. With the construction of the English logic by mind map, Chinese learners can enhance their English proficiency autonomously. 


\section{REFERENCES}

[1] 托尼.巴赞 ( Tony Buzan)李斯译，思维导图[M]. 北京：作家出版社，1999.

[2] Willis, CL., Mind maps as active learning tools, Journal of computing sciences in colleges, 2006. Volume: 21 Issue: 4.

[3] Joan Pinkham, The translators' Guide to Chinglish. Beijjing: Foreign language teaching and Research Press, 2000.

[4] Zhilun He, A Contrastive Analysis of the Semantic Structure Differences between Chinese and English from the Perspective of Thinking Mode, Master's thesis of University of Electronic Science and Technology of China, 2007

[5]贾竑、随晓冰, 思维导图应用于我国外语教学研究综述分析, 《中国电力教育》, 2014(1):189-191. 